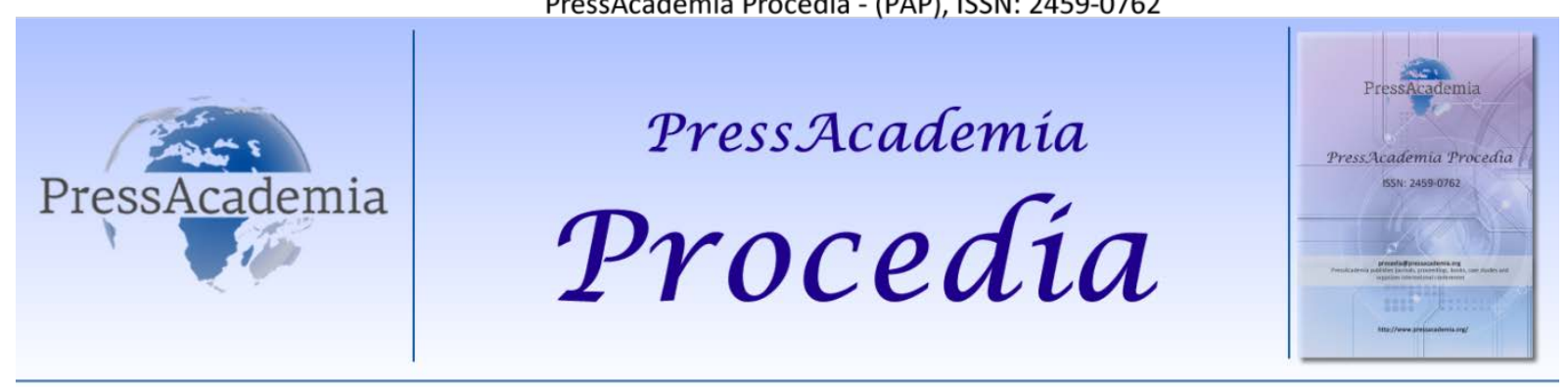

Global Business Research Congress (GBRC), May 26-27, 2016, Istanbul, Turkey.

\title{
UNIVERSITY STUDENTS AND MOBILE COMMERCE: A STUDY AT BILECIK SEYH EDEBALI UNIVERSITY
}

\section{DOI: 10.17261/Pressacademia.2016118673}

\section{Ali Acilar ${ }^{1}$, Aykut Hamit Turan ${ }^{2}$}

${ }^{1}$ Bilecik Şeyh Edebali Üniversitesi. ali.acilar@bilecik.edu.tr

${ }^{2}$ Sakarya Üniversitesi, ahturan@sakarya.edu.tr

\begin{abstract}
As mobile devices such as smart phones and tablets have become important tools for communication and entertainment, especially among young generation, these mobile devices have also provided new opportunities for business and commerce. In this study, the use of mobile phones for shopping on the Internet among university students was investigated. The data of this study was collected with a survey instrument from participants of Business students at Bilecik Seyh Edebali University. Based on the analysis of 278 Business students' data, we found that smart phone ownership is very common (97\%), students intensively use mobile phones (most of them use it at least 3 hours in a day) and it was found that $53 \%$ of the participants used their mobile phones to make purchases on the Internet. The majority of students who did not shop from the Internet using a mobile phone stated that the most important reason was the security risk.
\end{abstract}

Keywords: Mobile commerce, smart phone, survey, university students

JEL Codes: L81, M39, 129, M19

\section{ÜNIVERSiTE ÖĞRENCILERI VE MOBiL TiCARET: BiLECiK ŞEYH EDEBALi ÜNIVERSiTESi ÖRNEĞi}

\section{ÖZET}

Akıllı telefonlar ve tabletler gibi mobil cihazlar dünya genelinde, özellikle gençler arasında, iletişim ve eğlencenin temel araçları haline geldiği gibi iş hayatı ve ticarette de yeni fırsatlar oluşturmuştur. Bu araştırmada, üniversite öğrencileri arasında internette alışveriş için cep telefonu kullanımı araştırımıştır. Çalışmada Bilecik Şeyh Edebali Üniversitesi, iktisadi ve idari Bilimler Fakültesi, İşletme Bölümü öğrencilerine yapılan anket sonucunda elde edilen veriler analiz edilmektedir. Değerlendirmeye tabi tutulan 278 anket verilerine göre üniversite öğrencileri arasında akıllı telefon sahipliğinin çok yaygın olduğu (\%97), öğrencilerin yoğun bir şekilde cep telefon kullandığı (çoğunluğu günde en az 3 saat) ve araştırmaya katılan öğrencilerin \%53'ünün cep telefonunu kullanarak internetten alışveriş yaptı̆̆ı saptanmıştır. Cep telefonunu kullanarak internetten alışveriş yapmayan öğrencilerin çoğunluğu bunun en önemli nedeninin güvenlik riski olduğunu belirtmiştir.

Anahtar Kelimeler: Mobil ticaret, akıllı telefon, anket, üniversite öğrencileri JEL Kodları: L81, M39, 129, M19

\section{GíRiş}

Bilgi ve iletişim teknolojileri baş döndürücü bir hızla gelişmekte ve bu teknolojilerin kullanımı, gerek iş dünyasında, gerekse günlük yaşamda dünya genelinde yaygınlaşmaktadır. Son elli yıl içerisinde bilgi ve iletişim 
teknolojilerinde önemli gelişmeler olmuştur. Günümüzde etkisi gözlenen donanım eğilimleri şebeke bilgi işlem, sanallaştırma, bulut bilgi işlem, yeşil bilgi işlem, güç tasarruflu/yüksek performanslı işlemciler, otonom bilgi işlem ve gelişmekte olan mobil dijital platformdur (Laudon \& Laudon, 2011, 181). Günümüzde kablosuz ve mobil ağlar ve cihazların kullanımı, dünya genelinde yaygınlaşmaktadır (Ngai ve Gunasekaran, 2007). Yakın zamanda, akıllı telefonlar ve tablet bilgisayarlar gibi mobil cihazların internete erişim için birincil araçlar olacakları öngörülüyordu (Laudon \& Laudon, 2011, 181). Günümüzde bu öngörünün gerçekleşmiş olduğunu söyleyebiliriz.

Türkiye İstatistik Kurumu (TÜiK) 2015 yılı Hanehalkı Bilişim Teknolojileri Kullanım Araştırması sonuçlarına göre ev ve iş yeri dışında internet kullanımı için taşınabilir cihaz kullanımı arttı; araştırma kapsamında 2015 yılının ilk üç ayında interneti kullanan bireylerin \%74,4'ü ev ve işyeri dışında internete kablosuz olarak bağlanmak için cep telefonu veya akıllı telefon kullanırken, $\% 28,9$ 'u taşınabilir bilgisayar (dizüstü, tablet vb.) kullandığı saptanmış olup, bu oranlar 2014 yılının aynı döneminde sırasıyla \%58 ve \%28,5 olduğu saptanmıştır.

Günümüzde genel olarak veri, ses ve görüntü aktarımları internet teknolojilerine dayanmaktadır ve internet teknolojilerinin bunlar üzerindeki etkisi her geçen gün artmaktadır, ayrıca gerek ses gerekse veri aktarımı daha güçlü (hızlı), daha portatif (daha küçük ve mobil) ve daha ucuz hale gelmiştir (Laudon \& Laudon, 2011, 247). Bilgi ve iletişim teknolojilerinin hızlı gelişimi ile birlikte çeşitli mobil uygulamalar da popüler olmuştur; insanlar akılı telefon, tablet vb. mobil cihazlarını kullanarak hemen her yerde oyun oynayabilmekte, e-postalarını kontrol edebilmekte, sosyal ağ ve paylaşım sitelerini kullanabilmekte, borsayı takip edebilmektedir (Chen, Li, Chen \& Xu, 2011).

Mobil teknolojiler dünya genelinde hızı bir şekilde kabul görmüş ve benimsenmiş olsa da yayılma modelleri ülkeden ülkeye farklılık gösterebilmektedir (Dholakia, Dholakia, Lehrer \& Kshetri, 2004). Ülkeler arasındaki mobil teknolojilerin benimsenmesi ve kullanımı ile ilgili farklılıklar, mobil telekomünikasyon altyapısı farklııılarına, sunulan mobil ticaret hizmet yelpazesine, servis sağlayıcıları tarafından kullanılan pazarlama stratejilerine ve mobil ticaret hizmetleri tüketicilerin altında yatan kültüre atfedilebilir (Harris, Rettie ve Kwan, 2005).

Pew Araştırma Merkezi Şubat 2016 raporuna göre akıllı telefon kullanımı Avrupa ve Amerika gibi gelişmiş ülkelerin bulunduğu kıtalarda gelişmekte olan ülkelere göre daha yaygındır (Pew Research Center, 2016). Nüfus içerisinde internet ve akıllı telefon kullananların oranları, genel ülke zenginliği ile ilişkili olup, zengin ülkeler daha yüksek internet erişimi ve daha yüksek akıllı telefon sahipliği oranlarına sahip olma eğilimindedir (Pew Research Center, 2016). Pew Araştırma Merkezi Şubat 2016 raporuna göre akıllı telefon sahipliği oranının en yüksek olduğu ülke Güney Kore (\%88) iken ülkemizde akıllı telefona sahip olduğunu belirtenlerin oranı \%59'dur. TÜiK 2015 yılı Hanehalkı Bilişim Teknolojileri Kullanım Araştırması sonuçlarına göre ise ülkemizde 2015 yılı Nisan ayında araştırmaya katılan hanelerin $\% 96,8$ 'inde cep telefonu veya akıllı telefon bulunmaktadır ve sabit telefon bulunma oranının \%29,6 olduğu tespit edilmiştir.

\section{LITERATÜR TARAMASI: MOBIL TICARET}

Hızla büyüyen internet ve mobil iletişim sektörlerinin birleşimi, mobil ticaret için gelişmekte olan bir piyasa oluşmasına yol açmıştır (Islam, Ahmad, Khan \& Ali, 2010). Gelişmiş kablosuz ve mobil teknolojiler e-ticaretin kablosuz bir ağda gerçekleşmesine olanak sağlamaktadır (Ngai \& Gunasekaran, 2007). Mobil ticaret (m-ticaret), internete erişilebilen kablosuz bir cihaz üzerinden herhangi bir yerden mal veya hizmet satın alabilmektir ve mobil ağ üzerinden mobil cihazlarla yapılan parasal değeri olan herhangi bir işlem anlamına gelmektedir (Clarke, 2008). Diğer bir tanıma göre, m-ticaret, mal veya hizmeti kullanmak için mülkiyet veya hak devrini içeren herhangi bir işlemin, elektronik bir cihaz (tablet, akılı telefon vb) yardımıyla bilgisayar ortamlı ağlara mobil erişim kullanılarak başlatılması ve/veya tamamlanması anlamına gelir (Khalifa, Cheng \& Shen, 2012).

Mobil cihazlarla internette yapılabilecek işlemler mümkün olmakla birlikte, farklı dinamikleri ve farklı iş kuralları olan m-ticaret, web sitelerinin mobil cihazlara uyarlanması şeklinde basite indirgenecek bir konu da değildir (Özmen, 2013, 213). M-ticaretin temel karakteristik özellikleri şu şekilde sıralanabilir (Ding, lijima \& Ho, 2004): aynı anda birçok yerde bulunma (ubiquity), uygunluk (convenience), ulaşılabilirlik (accessibility), kişiselleştirme 
(personalization) ve yerelleştirme, yerini belirleme (localization). İnternet erişimli mobil cihaz kullanıcıları istediği yer ve zamanda istediği bilgiye ulaşabilmekte ve işlem yapabilmektedir; mobil cihazlar elinizin altında kolaylıkla erişilebilir; mobil cihaz kullanıcısı hemen her zaman ve her yerde ulaşılabilir; mobil cihazlarda kullanıcının özel isteklerine uygun hizmetler verebilme olanağı bulunmaktadır; mobil cihaz kullanıcısının herhangi bir anda nerede olduğu bilinebilir ve kullanıcının fiziksel konumu bilgisi mobil ticarete için önemli bir değer katar, konuma dayalı hizmet ve teklifler sunulabilir (Ding, lijima \& Ho, 2004; Keng, Ee-Peng \& Zixing, 2003).

M-ticaret dolaysız ve dolaylı m-ticaret olarak ikiye ayrılabilir (Özmen, 2013, 214). Doğrudan mobil ticaret, ticari işlem sürecinin; sipariş vermekten hatta arama yapmaktan başlayıp siparişin verilmesi, ödemenin gerçekleşmesi, siparişin teslim alınmasına ve satış sonrası hizmetlere kadar tüm işlemlerin doğrudan bir mobil cihaz üstünden yapılması şeklinde tanımlanabilir (Özmen, 2013, 214). Mobil cihazlar kullanılarak, mobil web tarayıcılarıyla mevcut web siteleri üstünden veya bu sitelerin mobil cihazlara uyarlandığı mobil siteler üstünden gerçekleşebileceği gibi mobil cihazlar için geliştirilen uygulamaların (apps) kullanılması ile de mobil cihazlar üzerinden alışveriş yapmak mümkündür (Özmen, 2013, 214).

Dolaylı m-ticaret ise mobil cihazlar kullanılarak geleneksel veya web ortamında gerçekleşen ticari faaliyetlere değer katan uygulamalardır (Özmen, 2013, 215). Dolaylı m-ticaret uygulamalarına aşağıdaki örnekler verilebilir (Özmen, 2013, 215):

- Lokasyon bazlı servisler kullanarak perakendeciye yönlendirmek.

- Tüketiciyi satın almaya teşvik etmek için mobil cihazlarla gerçek zamanlı anlık teklifler sunmak.

- $\quad$ Fiziki mağazalarda ürün bilgilerine erişim sağlayan kare kod vb. optik okuyucular.

- Internetten eş zamanlı fiyat karşılaştırması.

- Tüketicinin bir perakendecideyken, restoran, kafe, otel veya bir eğlence merkezindeyken gelişini bildirmesi (check in) ve bunu sosyal medyada paylaşması.

- Tüketicileri fiziksel mağazalara yönlendirmek için mobil cihazlar üstünden mobil kupon dağıtılması.

\subsection{TÜRKIYE'DE MOBIL TICARET}

Dünya genelinde olduğu gibi ülkemizde de mobil altyapı ve mobil teknolojilerin gelişmesi ile cep telefonları ve tablet bilgisayarlar gibi mobil cihazların yaygın bir şekilde kullanılmaya başlaması m-ticaretin de toplum içerisinde yaygınlaşmasında önemli bir etkisi olmuştur. Cisco Mobil Görsel Ağ Endeksi tahminine göre Türkiye'nin de içinde bulunduğu Orta ve Doğu Avrupa Bölgesi'nde mobil veri trafiğinin 2014- 2019 yılları arasında yüzde 71'lik büyüme oranıyla 14 kat artması beklenmektedir (Cisco, 2015). Cisco Mobil Görsel Ağ Endeksi tahminine göre 2014- 2019 yılları arasında bölgedeki mobil veri trafiği sabit IP trafiğinin 3 katı daha hızlı artacağı, 2019 yılında bölgedeki mobil veri trafiğinin, toplam trafiğin (mobil ve sabit) yüzde 26’sını oluşturacağı öngörülmektedir.

OECD 2015 yılı Dijital Ekonomi Görünüm (Digital Economy Outlook) raporuna göre OECD ülkelerinin genelinde bir mobil cihaz kullanarak mal veya hizmet siparişi verenler arasında akıllı telefon kullanıcılarının payı 2001 yılında \%24 iken 2013 yılında \%38'e artmıştır, ülkemiz için bu oran rapora göre 2013 yılında \%34'tür (Grafik 1). 
Grafik 1: OECD Ülkelerinde Akıllı Telefonlarla Mal veya Hizmet Satın Alımı Internet Kullanan Akıllı Telefon Kullanıcılarının Yüzdesi

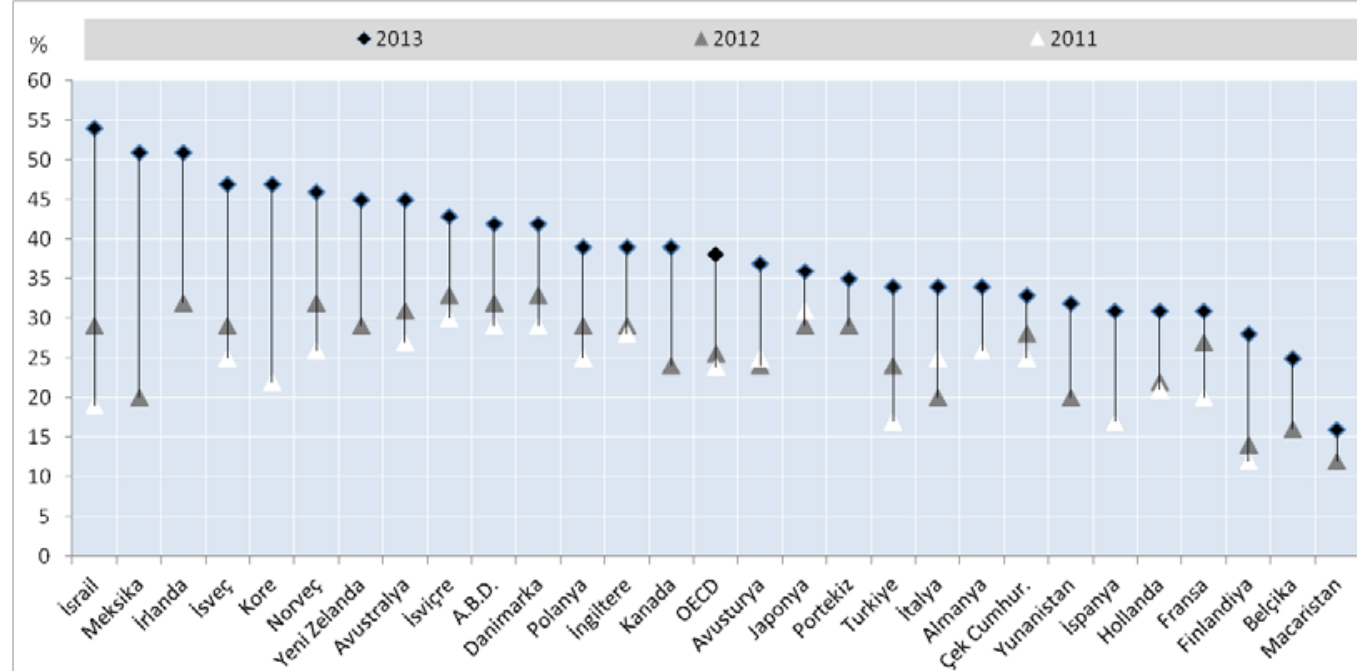

Kaynak: OECD Digital Economy Outlook 2015: p248.

Fiyat ve karşılaştırma sitesi Bilio.com’un, 13-18 Kasım 2015 tarihleri arasında web sitesi üzerinden 1.500 kişi ile yaptığı mobil alışveriş alışkanlıkları anketi sonuçlarına göre (eticaretdergi.com, shiftdelete.net);

- Ankete katılanların \%40’ının akıllı telefonu üzerinden alışveriş yaptığı, \%60'ının ise akıllı telefonlarından hiç alışveriş yapmadığı,

- Akıllı telefonları üzerinden alışveriş yaptıklarını belirten kişilerin \%85'inin, mobil alışveriş için akılı telefon yerine tableti tercih ettiği,

- Mobil alışveriş yapanların \%48'i kullanım kolaylığı, \%36'sının fırsatları kaçırmamak, \%16'sı da güvenli bir alışveriş deneyimi yaşamak için mobil alışverişi tercih ettikleri,

- Anket katılımcısı mobil alışveriş yapanların, \%50'sinin teknoloji ürünlerini satın aldığı, geri kalan kısım ise yüzde ağırlığına göre sırasıyla moda, kozmetik ve dekorasyon ürünleri satın aldıkları,

- Ankete katılanların \%61'inin alışveriş yapacakları sitenin mobil uygulaması olmasının veya web sitesinin mobil cihazlara uyumlu olarak erişilmesinin, mobil alışveriş kararlarını etkileyeceğini belirttiği,

- Ankete katılan akıllı telefon kullanıcılarının \%46'sının web siteleri üzerinden alışveriş yapmayı tercih ederken, \%54'ünün de e-ticaret sitelerinin farklı telefon işletim sistemleri için özel olarak geliştirdiği mobil uygulamaları kullandığı saptanmıştır.

Türkiye'de tüketicilerin mobil alışkanlıklarını incelemek amacıyla 1.550 kişinin katılımıyla gerçekleştirilen ve Capital Dergisi Ocak 2016 Mobil Ticaret Özel Sayısında yayınlanan “Mobil Alışveriş ve Ödeme Alışkanlıkları” araştırması sonuçlarına göre ise;

- Interneti olan her 4 kişiden 1'i online alışveriş yaparken, online alışveriş yapan her 3 kişiden 1'i ise mobil alışveriş yapmaktadır.

- Tüketicilerin mobil alışverişi tercih etmesindeki en önemli nedenler; pratiklik, hız ve ürün araştırması yapmadaki kolaylık ve kampanya fırsatları olarak öne çıkmaktadır.

- Mobil ödemenin önündeki en önemli bariyer olarak tüketicilerin kişisel bilgilerinin çalınmasına ilişkin endişesi öne çıkmaktadır, mobil alışveriş yapan her 5 tüketiciden 4’ü kişisel bilgi hırsızlığından çekinmektedir. 
Online alışveriş yapıp mobil cihazla alışveriş yapmayan tüketicilerin alışverişte mobil cihaz kullanmamasının en önemli sebebi mevcuttaki masa üstü veya dizüstü bilgisayar alışkanlıkları olup, bu alışkanlığın yanında özellikle mobil web sitelerindeki sorunlar tüketicilerin mobil alışveriş yapma tercihlerini olumsuz olarak etkilemektedir.

- Mobil alışveriş en çok 25-34 yaş arasındaki kişiler tarafından yapılmaktadır

- Mobil alışveriş yapanlar arasında en çok tercih edilen sektörler sırasıyla; giyim, elektronik aletler ve seyahat/konaklamadır.

- Mobil alışveriş için uygulama kullanan tüketicilerin, satın alma ve ödeme yapma ihtimaliyle sıklığı sadece

mobil web sitesi kullananlara göre daha yüksektir.

Mobil cihazlar sadece alışveriş yapmak için değil aynı zamanda alışveriş için bilgi edinme amaçlı olarak da kullanılabilmektedir. Akıllı telefon kullanılarak elde edilen ürün veya hizmetle ilgili bilgiler, çevrimiçi veya çevrimdışı alışveriş kararını etkileyebilmektedir (OECD, 2015). "Mobil Alışveriş ve Ödeme Alışkanlıkları" araştırması sonuçlarına göre mobil cihazlar alışverişin araştırma/karşılaştırma aşamasında, ödeme aşamasına kıyasla çok daha yoğun kullanılmaktadır. Aynı araştırmaya göre, mobil alışveriş yapan tüketicilerin yarısından fazlası alışveriş esnasında mağaza içinde mobil cihazlarını kullanıyor olup, bunlar içerisinde her 2 tüketiciden $1^{\prime} \mathrm{i}$ fiyat karşılaştırması yaparken, her 3 tüketiciden 1'inin ürüne ilişkin yorum okuduğu, her 4 tüketiciden 1'inin de mobil cihazını kampanya kuponu/promosyonu almak için, her 5 tüketiciden 1 'inin de barkod uygulaması için mağaza içinde mobil cihazını kullandığı saptanmıştır.

\section{VERI VE YÖNTEM}

Bu çalışmada veri toplama yöntemi olarak anket yöntemi benimsenmiştir. Anket hazırlanırken, Kini (2009), Rahman \& Sloan (2015), Harris, Rettie \& Kwan (2005), Lee, H.H. \& Lee, S. E. (2007) çalışmalarından yararlanılmıştır ve Türkçe'ye uyarlanmıştır. Anket 23 Şubat - 25 Şubat 2016 tarihleri arasında Bilecik Şeyh Edibali Üniversitesi, İktisadi ve İdari Bilimler Fakültesi, İşletme Bölümü lisans öğrencilerine uygulanmıştır. Anket çalışmasına 279 öğrenci katılmış ve 278 öğrenciden elde edilen veriler analiz edilmiştir. Bu çalışma genel olarak tanımlayıcı ve bir seri olarak planlanan çalışmalar bütününün ilk aşaması olarak planlanmıştır ve değerlendirilmiştir.

\section{VERILERIN ANALIZi}

Çalışmanın genel amacı, m-ticaret olgusunun lisans öğrencileri arasında yayılmasının ve genel olarak öğrencilerin bilişim ve iletişim teknolojileri kullanma karakteristiklerinin ölçülmesi olarak belirlenmiştir. Genel bulgular Tablo 1'de sunulmuştur.

Araştırma anketine katılanların büyük çoğunluğu kız öğrencilerdir ve tüm katılımcıların cep telefonunun olduğu saptanmıştır. Ankete katılan öğrencilerin ortalama yaşı 21 olup, en düşük yaşa sahip katılımcının 18, en büyük yaşa sahip katılımcının ise 30 yaşında olduğu saptanmıştır.

Günümüzde akıllı cep telefonu kullanımı toplum içinde oldukça yaygınlaşmıştır, çalışmaya katılan öğrencilerin de neredeyse tamamı $(\% 97,1)$ akıllı cep telefonuna sahiptir. Katılımcıların çoğunluğunun son bir yıl içerisinde cep telefonu operatörünü değiştirmemiş olduğu $(\% 64,7)$ ve büyük çoğunluğunun $(\% 93,2)$ sadece tek bir cep telefonuna sahip olduğu ve buna paralel olarak tek bir cep telefon numarası kullanmakta olduğu $(\% 92,1)$ tespit edilmiştir. Ankete katılan öğrenciler cep telefonlarını genellikle bozuldukça yenilediklerini ifade etmişlerdir (\%59) ve 4 yıldan daha az bir sürede cep telefonunu yenilediğini belirten öğrencilerin oranı \%35 olarak saptanmıştır. Ankete katılan öğrencilerin \%51'inin en son almış olduğu cep telefonuna 1000TL veya daha fazla ödediği saptanmıştır. Öğrencilerin bir ayda cep telefonu için harcadığı ortalama tutar genel olarak 40 TL'nin altındadır ve cep telefonu için bir ayda 50 TL'den fazla harcama yapanların oranı sadece \%6,8 olarak hesaplanmıştır. Tüm bunlara rağmen, öğrencilerin yoğun birer cep telefonu kullanıcısı oldukları anlaşılmaktadır. Günde ortalama 4 saatten fazla cep telefonu kullanan öğrencilerin oranı neredeyse yarıya yakındır $(\% 44,6)$. (Tablo 1) 
Tablo 1: Genel Bulgular

\begin{tabular}{|c|c|c|c|}
\hline Cinsiyetiniz & $\mathrm{n}(\%)$ & Cep Telefonu Kullanıyor musunuz? & $\mathrm{n}(\%)$ \\
\hline Kadın & $188(67,6)$ & Evet & $278(100,0)$ \\
\hline Erkek & $90(32,4)$ & Hayır & $0(0,0)$ \\
\hline Toplam & $278(100,0)$ & Toplam & $278(100,0)$ \\
\hline Cep telefonunuz akıllı telefon mu? & $\mathrm{n}(\%)$ & $\begin{array}{l}\text { Son bir yıl içerisinde cep telefonu } \\
\text { operatörünüzü değiştirdiniz mi? }\end{array}$ & $\mathrm{n}(\%)$ \\
\hline Evet & $270(97,1)$ & Evet & $94(33,8)$ \\
\hline Hayır & $8(2,9)$ & Hayır & $180(64,7)$ \\
\hline \multirow[t]{2}{*}{ Toplam } & $278(100,0)$ & Eksik veri & $4(1,4)$ \\
\hline & & Toplam & $278(100,0)$ \\
\hline $\begin{array}{l}\text { Hâlihazırda kullandığınız kaç tane cep } \\
\text { telefonunuz var? }\end{array}$ & $\mathrm{n}(\%)$ & $\begin{array}{l}\text { Hâlihazırda kullandığınız kaç tane cep } \\
\text { telefonu numaranız var? }\end{array}$ & $\mathrm{n}(\%)$ \\
\hline 1 & $259(93,2)$ & 1 & $256(92,1)$ \\
\hline 2 & $13(4,7)$ & 2 & $13(4,7)$ \\
\hline 3 & $3(1,1)$ & 3 & $1(0,4)$ \\
\hline 4 ve daha fazla & $2(0,7)$ & 4 veya daha fazla & $1(0,4)$ \\
\hline Eksik veri & $1(0,4)$ & Eksik veri & $7(2,5)$ \\
\hline Toplam & $278(100,0)$ & Toplam & $278(100,0)$ \\
\hline $\begin{array}{l}\text { Hangi sıklıkla cep telefonunuzu } \\
\text { yeniliyorsunuz? }\end{array}$ & $\mathrm{n}(\%)$ & $\begin{array}{l}\text { En son almış olduğunuz cep telefonuna } \\
\text { kaç TL ödediniz? }\end{array}$ & $\mathrm{n}(\%)$ \\
\hline Her 6 ayda bir & $0(0)$ & 500 TL den az & $24(8,6)$ \\
\hline Her yıl & $11(4,0)$ & 500-750TL arası & $58(20,9)$ \\
\hline Her 2 yılda bir & $45(16,2)$ & 750-1000 TL arası & $55(19,8)$ \\
\hline Her 3 yılda bir & $41(14,7)$ & $1000-1250$ TL arası & $34(12,2)$ \\
\hline Her 4 yılda bir & $15(5,4)$ & $1250-1500 \mathrm{TL}$ arası & $30(10,8)$ \\
\hline Bozuldukça & $164(59,0)$ & 1500-1750 TL arası & $23(8,3)$ \\
\hline Eksik veri & $2(0,7)$ & $1750-2000 \mathrm{TL}$ arası & $26(9,4)$ \\
\hline Toplam & $278(100,0)$ & 2000 TL den fazla & $28(10,1)$ \\
\hline & & Toplam & $278(100,0)$ \\
\hline $\begin{array}{l}\text { Bir ayda cep telefonunuz için ortalama } \\
\text { kaç TL harcıyorsunuz? }\end{array}$ & $\mathrm{n}(\%)$ & $\begin{array}{l}\text { Bir günde cep telefon kullanım süreniz } \\
\text { ortalama ne kadardır? }\end{array}$ & $\mathrm{n}(\%)$ \\
\hline 20 TL'den az & $26(9,4)$ & 30 dakikadan az & $9(3,2)$ \\
\hline $20-30 \mathrm{TL}$ arası & $145(52,2)$ & 30 dakika - 1 saat arası & $13(4,7)$ \\
\hline $30-40 \mathrm{TL}$ arası & $63(22,7)$ & $1-2$ saat arası & $28(10,1)$ \\
\hline $40-50 \mathrm{TL}$ arası & $21(7,6)$ & $2-3$ saat arası & $53(19,1)$ \\
\hline 50 TL'den fazla & $19(6,8)$ & $3-4$ saat arası & $49(17,6)$ \\
\hline Eksik veri & $4(1,4)$ & 4 saatten fazla & $124(44,6)$ \\
\hline Toplam & $278(100,0)$ & Eksik veri & $2(0,7)$ \\
\hline & & Toplam & $278(100,0)$ \\
\hline
\end{tabular}

Anket katılımcılarına cep telefonlarını kullanarak internetten hiç alışveriş yapıp yapmadıkları sorulmuştur. Anket katılımcılarının 147'si (\%52,9) cep telefonlarını kullanarak internetten alışveriş yaptıklarını, 128 kişi (\%46) cep telefonlarını kullanarak internetten alışveriş yapmadıklarını belirtmişlerdir (Tablo 2). Katılımcıların yarısından biraz fazlasının cep telefonları ile internetten alışveriş yaptığı saptanmıştır. Bu durum, mobil cihazlar üzerinden alışveriş yapmanın çalışmaya katılan üniversite öğrencileri arasında çok fazla yaygın olmadığının bir göstergesi olarak kabul edilebilir.

Anket katılımcılarına ayrıca eğer mobil telefonunuz ile internetten alışveriş yaptıysanız, şu ana kadar toplam kaç kere yaptınız sorusu da sorulmuştur. Cep telefonunu kullanarak internetten alışveriş yapan katılımcıların 
çoğunluğuna denk gelen 82 kişi $(\% 55,8) 1$ ile 5 kere arası, 33 kişi $(\% 22,4) 5$ ile 10 kere arası, 16 kişi $(\% 10,9) 10$ ila 15 kere arası ve 16 kişi $(\% 10,9)$ de 15 kere veya daha fazla cep telefonunu kullanarak internetten alışveriş yaptığını belirtmiştir. Bu durum, mobil cihazlar üzerinden alışveriş̧in genç üniversite öğrencileri arasında bile daha yeni yaygınlaşan bir olgu olduğunu ve araştırmamıza katılan öğrencilerin çoğunun oldukça az sayıda internet alışverişini cep telefonlarından zaman içerisinde yaptığını ortaya koymuştur. Cep telefonunu kullanarak internetten alışveriş yapmayanların, bu kararlarını etkileyen en önemli neden olarak güvenlik riski ön plana çıkmaktadır. Cep telefonunu kullanarak internetten alışveriş yapmayanların \%63,3'ü (81 kişi) bunun en önemli nedeninin "güvenlik riski" olduğunu belirtmiştir. Cep telefonunu kullanarak internetten alışveriş yapmayan katılımcılara ilerde cep telefonunu kullanarak internetten alışveriş yapma niyetleri sorulduğunda sadece $\% 5,5^{\prime} \mathrm{i}$ bu niyetin fazla veya çok fazla olduğunu belirtmiş ve geri kalan büyük çoğunluk $(118$ kişi, \%92,2) ise ilerde cep telefonunu kullanarak internetten alışveriş yapma niyetlerinin orta, az veya hiç yok şeklinde ifade etmiştir (Tablo 2).

Tablo 2: Katılımcıların M-Ticaret Yapma Durumu

\begin{tabular}{|l|c|}
\hline Cep telefonunuzu kullanarak internetten alışveriş yaptınız mı? & $\mathrm{n}(\%)$ \\
\hline Evet & $147(52,9)$ \\
Hayır & $128(46,0)$ \\
Eksik veri & $3(1,1)$ \\
Toplam & $278(100,0)$ \\
\hline Cevabınız Evet ise cep telefonunuzu kullanarak internetten şimdiye & \\
kadar kaç kere alışveriş yaptınız? & $\mathrm{n}(\%)$ \\
\hline $1-5$ arası & $82(55,8)$ \\
$5-10$ arası & $33(22,4)$ \\
$10-15$ arası & $16(10,9)$ \\
$15-20$ arası & $2(1,4)$ \\
20 veya daha fazla & $14(9,5)$ \\
Toplam & $147(100,0)$ \\
\hline Cevabınız Hayır ise cep telefonunuzu kullanarak internetten alışveriş & \\
yapmamanızda en önemli neden nedir? & $\mathrm{n}(\%)$ \\
\hline Kullanım karmaşıklığı & $12(9,4)$ \\
İnternet erişim hızı & $5(3,9)$ \\
Güvenlik riski & $81(63,3)$ \\
Servis kalitesinin düşüklüğü & $3(2,3)$ \\
Yeterince kişileştirilmemiş servis & $4(3,1)$ \\
Diğer & $9(7,0)$ \\
Eksik veri & $14(10,9)$ \\
Toplam & $128(100,0)$ \\
\hline Cep telefonunuzu kullanarak internetten alışveriş yapmadıysanız ileride & \\
yapma niyetiniz ne kadardır? & $\mathrm{n}(\%)$ \\
\hline Hiç yok & $29(22,7)$ \\
Az & $42(32,8)$ \\
Orta & $47(36,7)$ \\
Fazla & $6(4,7)$ \\
Çok fazla & $1(0,8)$ \\
Topsik veri & $3(2,3)$ \\
\hline
\end{tabular}

\section{SONUÇ}

Günümüzde mobil cihazların kullanımı dünya genelinde hem gelişmiş, hem de gelişmekte olan ülkelerde gittikçe artmaktadır. Özellikle genç nesiller arasında mobil cihazlar çok önemli bir kullanım potansiyeline sahiptir. Son yıllarda mobil cihazlar üzerinde elektronik ticaret de gittikçe artmakta ve bu durum hem 
akademisyenlerin hem de uygulamacıların dikkatini çeken bir konu olmaktadır. Bu çalışmada Bilecik Şeyh Edibali Üniversitesi lisans öğrencileri arasında internette alışveriş için cep telefonu kullanımı incelenmiştir. Çalışmada verilerin toplanması amacıyla anket yöntemi kullanılmıştır.

Anket katılımcısı lisans öğrencilerinin tamamının cep telefonuna sahip olduğu, bunların da neredeyse tamamının akıllı telefon olduğu ve öğrencilerin cep telefonlarını yoğun bir şekilde kullandıkları saptanmıştır. Ancak, cep telefonunu kullanarak internetten alışveriş yapmanın çalışmaya katılan öğrenciler arasında çok fazla yaygın olmadığı, katılımcıların \%46'sının cep telefonu üzerinden internette alışveriş yapmadıkları ve yapanların da genel olarak oldukça düşük sayılarda alışveriş yaptığı tespit edilmiştir. Katılımcıların cep telefonunu kullanarak internetten alışveriş yapmamasının en önemli nedeninin güvenlik riski olduğunu saptanmıştır. Cep telefonunu kullanarak internetten alışveriş yapmayan katılımcıların büyük çoğunluğunun ilerde cep telefonunu kullanarak internetten alışveriş yapma niyetlerinin fazla olmadığı anlaşılmaktadır.

\section{KAYNAKLAR}

Capital, Ocak 2016, Mobil Ticaret Özel Sayısı

http://bkm.com.tr/wp-content/uploads/2015/06/BKMdergi.pdf, Erişim Tarihi: 05.04.2016.

Chen, Z., Li, R., Chen, X. \& Xu, H. (2011). A Survey Study on Consumer Perception of Mobile-Commerce Applications, Procedia Environmental Sciences, 11, 118-124.

Cisco (2015). 12 Şubat 2015 Basın Bülteni: Mobil Veri Trafiğinin Yüzde 88'i Akıllandı, http://www.cisco.com/web/TR/news/press/archive/2015/120215.html Erişim Tarihi: 29.04.2016.

Clarke III, I. (2008). Emerging Value Propositions for M-commerce, Journal of Business Strategies, 25(2), 41-57.

Dholakia, N., Dholakia, R.R., Lehrer, M. \& Kshetri, N., (2004). Global Heterogeneity in the Emerging M-Commerce Landscape. In N. Shi (Ed.), Wireless Communications and Mobile Commerce (pp. 1-22), Hershey PA: Idea Group Inc.

Ding, X., lijima, J. \& Ho, S. (2004). Unique Features of Mobile Commerce, Journal of Electronic Science and Technology of China, 2(3), 205210.

Harris, P., Rettie, R. \& Kwan, C. C. (2005). Adoption and Usage of M-Commerce: A Cross-Cultural Comparison of Hong Kong and the United Kingdom, Journal of Electronic Commerce Research, 6(3), 210-224.

Islam, A., Ahmad, T.S.B., Khan, M.A. ve Ali, M.H. (2010). Adoption Of M-Commerce Services: The Case Of Bangladesh, World Journal of Management, 2 (1), 37-54.

Keng, S., Ee-Peng, L. \& Zixing, S. (2003). Mobile Commerce: Current States and Future Trends. In S. Keng \& L., Ee-Peng (Ed.), Advances in Mobile Commerce Technologies (pp. 1-17), Hershey PA: Idea Group Inc.

Khalifa, M., Cheng, S. K. N. \& Shen K.N. (2012). Adoption of Mobile Commerce: A Confidence Model, Journal of Computer Information Systems, 53(1), 14-22.

Kini, R. B. (2009). Adoption and Evaluation of Mobile Commerce in Chile, The Electronic Journal Information Systems Evaluation, 12(1), 7588

Laudon, K.C., \& Laudon, J.P. (2011). Yönetim Bilişim Sistemleri Dijital Iş̧letmeyi Yönetme. U. Yozgat (Çev). 12. Basım. Nobel Yayınları, Ankara. Lee, H.H. \& Lee, S. E. (2007). Mobile Commerce: An Analysis of Key Success Factors, Journal of Shopping Center Research, 14(2), $29-62$.

Ngai, E.W.T. \& Gunasekaran, A. (2007). A Review for Mobile Commerce Research and Applications, Decision Support Systems, $43,3-15$.

OECD (2015), OECD Digital Economy Outlook 2015, OECD Publishing, Paris.

DOI: http://dx.doi.org/10.1787/9789264232440-en, Erişim Tarihi: 04.04.2016

http://www.oecd.org/publications/oecd-digital-economy-outlook-2015-9789264232440-en.htm, Erişim Tarihi: 04.04.2016.

Pew Research Center, February, 2016, Smartphone Ownership and Internet Usage Continues to Climb in Emerging Economies,

http://www.pewglobal.org/files/2016/02/pew research center global technology report final february 22 2016.pdf, Erişim Tarihi: 01.04.2016. 
Rahman, M. M. \& Sloan, T. (2015). Opportunities and Challenges of M-Commerce Adoption in Bangladesh: An Empirical Study, Journal of Internet Banking and Commerce, 20(3), 1-9.

Şule, Ö. (2013). Ağ Ekonomisinde Yeni Ticaret Yolu: E-Ticaret, Genişletilmiş 5. Baskı, İstanbul Bilgi Üniversitesi Yayınları, İstanbul.

TÜiK (2015). Hanehalkı Bilişim Teknolojileri Kullanım Araştırması, http://www.tuik.gov.tr/PreTablo.do?alt id=1028 , Erişim Tarihi: 18.02.2016.

Mobil Alışveriş Uygulamaları Revaçta!

http://shiftdelete.net/mobil-alisveris-uygulamalari-revacta-66057, Erişim Tarihi: 04.04.2016.

Bilio.com Mobil Alışveriş Alışkanlıkları Anketi

http://www.eticaretdergi.com/bilio-com-mobil-alisveris-aliskanliklari-anketi/, Erişim Tarihi: 04.04.2016. 